\title{
Erratum to: Quantification of floating ephippia in lakes: a step to a better understanding of high dispersal propensity of freshwater plankters
}

\author{
Mirosław Ślusarczyk • Tomasz Grabowski • \\ Barbara Pietrzak
}

Published online: 21 September 2015

(C) Springer International Publishing Switzerland 2015

\section{Erratum to: Hydrobiologia DOI 10.1007/s10750-015-2437-4}

Due to an unfortunate turn of events, an error was introduced in the scale of the $y$ axis of Fig. 3 in the above mentioned publication. The correct image and its caption are published here and should be treated as definitive by the reader.
The online version of the original article can be found under doi:10.1007/s10750-015-2437-4.

M. Ślusarczyk $(\bowtie) \cdot$ T. Grabowski · B. Pietrzak Department of Hydrobiology, Faculty of Biology, University of Warsaw Biological and Chemical Research Centre, Żwirki i Wigury 101, 02-089, Warsaw, Poland e-mail: m.slusarczyk@uw.edu.pl

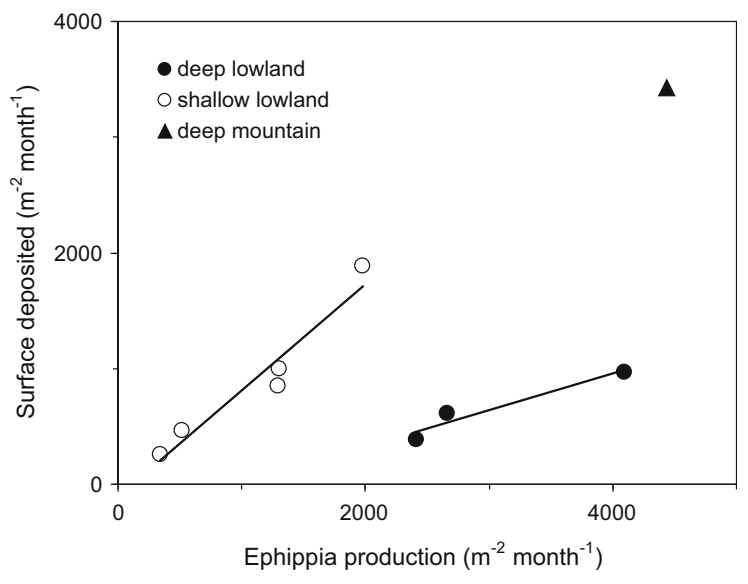

Fig. 3 Estimated densities of floating ephippia versus overall densities of ephippia accumulated during a month of ephippia formation period 